\title{
Venus and solar storms: Solar Energetic Particles, Stream Interaction Regions and Coronal Mass Ejections
}

\author{
Shannon Curry ${ }^{1}$, Janet Luhmann ${ }^{1}$, Candance Gray ${ }^{2}$, Glyn Collinson ${ }^{3}$
}

${ }^{1}$ Space Science Laboratory, University of California, Berkeley, CA 94720, ${ }^{2} \mathrm{New}$ Mexico State University - Apache Point Observatory, 1780 E University Ave, Las Cruces, NM 88003, ${ }^{3}$ NASA Goddard Space Flight Center

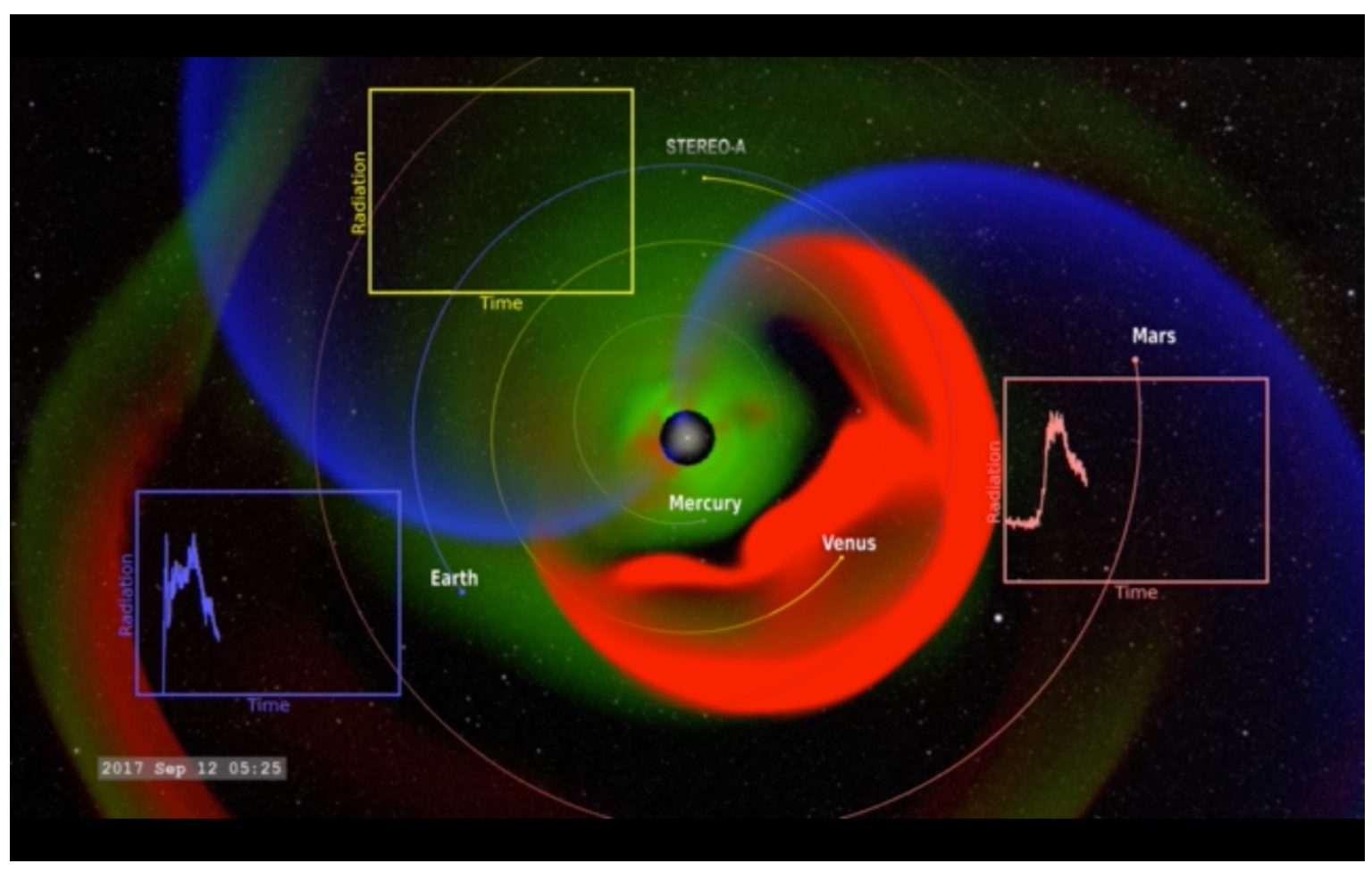

Shannon Curry $561-972-8127$

Space Sciences Laboratory, University of California, Berkeley smcurry@berkeley.edu 